\title{
Observed Clinical, Laboratory, and Echocardiographic Parameters in Takotsubo Syndrome Patients with Mortality and Decreased Ejection Fraction During Initial Hospital Admission
}

\author{
Andrew Hinojos, DO', Thomas E. Vanhecke, MD², Stephen Manning, DO ${ }^{3}$ \\ 1 Genesys Heart Institute, PGY-5 Cardiology Fellow, Grand Blanc, MI, 2 Genesys Heart Institute Attending Cardiologist, Grand Blanc, MI, 3 Genesys \\ Regional Medical Center/Ascension Health PGY-1 Internal Medicine Resident, Grand Blanc, MI \\ Keywords: heart failure, cardiomyopathy, acute coronary syndrome, takotsubo syndrome \\ https://doi.org/10.51894/001c.6941
}

\section{Spartan Medical Research Journal}

Vol. 3, Issue 2, 2018

\begin{abstract}
CONTEXT
Approximately 1-2\% of patients with suspected acute coronary syndrome also develop Takotsubo syndrome (TTS). This syndrome is characterized by transient systolic dysfunction of the apical and/or mid segments of the left ventricle that mimics myocardial infarction in the absence of obstructive coronary artery disease. Up to $21.8 \%$ of TTS patients develop serious complications, including death. Currently, there is no consensus on management of these patients and their complications. Thus, identifying TTS patients at higher risk for complications becomes valuable in managing their hospital course. The aim of this study was to examine the predictive significance of laboratory, echocardiographic, and clinical parameters on in-hospital mortality in a sample subgroup of TTS patients. Secondary analyses were performed on patients with reduced (i.e., <35\%) ejection fractions.
\end{abstract}

\section{METHODS}

This retrospective study at a community hospital identified patients from October 1, 2009 to August 31, 2015 who presented with ACS and underwent cardiac catheterization. Patients were diagnosed with TTS by features of cardiomyopathy on cardiac catheterization or echocardiogram.

\begin{abstract}
RESULTS
The authors analyzed data from a total of 177 eligible patients identified with TTS. The in-hospital mortality rate was $5.65 \%$. Compared to the non-mortality subgroup, patients who suffered in-hospital mortality had significantly lower diastolic blood pressure on admission ( $p<0.050)$, lower hemoglobin levels $(p<0.001)$, lower sodium $(p=0.020)$, higher blood urea nitrogen $(p=0.009)$, lower glomerular filtration rate $(p=0.016)$, and lower albumin levels $(\mathrm{p}<0.001)$. Cox regression analyses demonstrated admission hemoglobin was significant, yielding a mortality hazard ratio of 0.760 (95\% CI of $0.594-0.972, \mathrm{p}=0.029$ ).
\end{abstract}

\section{CONCLUSIONS}

Patients who present with TTS and hypotension, anemia, low albumin levels, elevated lactic acid and renal dysfunction were associated with higher rates of in-hospital mortality in this study's sample population. Further, admission hemoglobin had the strongest association with death. Every unit decrease in hemoglobin increased mortality risk by $24 \%$.

\section{INTRODUCTION}

Takotsubo (or "Tako-Tsubo") syndrome (TTS) is characterized by transient systolic dysfunction of the apical and/or mid segments of the left heart ventricle mimicking myocardial infarction in the absence of obstructive coronary artery disease (CAD). ${ }^{1,2}$ Approximately 1-2\% of patients with sus- pected acute coronary syndrome (ACS) have been found to have TTS after cardiac catheterization. ${ }^{3}$ Several studies have shown that TTS is not a benign or transient syndrome, with complications in up to $21.8 \%$ of patients. ${ }^{4-6}$

Most common complications occur in the acute setting and include heart failure, tachyarrhythmias, mitral regurgitation, left ventricular (LV) outflow tract obstruction, and cardiogenic shock. ${ }^{2,7-9}$ Mortality rates have ranged from 
$1.1 \%$ to $10.2 \% .^{3,5,6,8-12}$ Although the pathogenesis of TTS is not completely understood, experts have concluded this syndrome is most likely due to a surge of catecholamines causing vascular dysfunction and direct myocardial stunning (i.e., reversible reduction of function of heart contraction after reperfusion). ${ }^{2,13-15}$

Clinicians' efforts to identify TTS patients at higher risk for complications and mortality are imperative, as traditional therapies for heart failure and cardiogenic shock have been limited and shown mixed results. ${ }^{16}$ Use of beta blockers to attenuate the cathecholamine surge does not appear to improve mortality, complication rates, or prevented recurrence. 5,17,18 Additionally, information regarding use of angiotensin converting enzyme inhibitors (ACEI) or aldosterone receptor blockers (ARB) is limited with potential benefits demonstrated in one retrospective study. ${ }^{18}$

In the severely ill TTS patient, management presents unique complications such as dynamic left ventricular outflow tract (LVOT) obstruction. Use of inotropes is generally regarded as a contraindication in TTS as they can worsen the dynamic LVOT obstruction. ${ }^{2,19}$ Previous case reports have also suggested poor outcomes with use of beta agonists and vasopressors. ${ }^{19,20}$ Thus, it remains critical to identify those TTS patients at greater risk for complications since there is still little conclusive evidence for treatment available. ${ }^{2,5}$

\section{PURPOSE OF STUDY}

The specific aim of the study was to examine the significance of key laboratory, clinical, and echocardiographic parameters observed in a sample subgroup of TTS patients whose hospital course was complicated and/or may have experienced in-hospital mortality.

\section{METHODS}

This study was a retrospective chart review approved by the local institutional review board in January, 2017 and conducted at a community-based hospital in Grand Blanc, Michigan. Patient data were obtained through electronic health records pulled by the first (AH) and third (SM) authors using ICD-9 codes 410.9 (myocardial infarction) and 429.83 (Takotsubo Syndrome) from October 1, 2009 to August 31, 2015..$^{21}$ The convenience sample included patients ages 18 and older who had presented as an acute myocardial infarction and underwent cardiac catheterization during their hospital stays.

Charts were reviewed independently by two separate cardiologists, and patients' TTS diagnosis was based on the Mayo Clinic Criteria and the 2016 European Society consensus statement. ${ }^{1,2}$ TTS was diagnosed in patients who had presented with ACS and demonstrated regional wall motion abnormalities without culprit atherosclerotic CAD (i.e., lesion(s) involved in an acute myocardial infarction). ${ }^{22,23}$

Each sample patient had received a cardiac catheterization to rule out acute plaque rupture, thrombus formation, coronary dissection or other pathological conditions that would explain observed patterns of temporary LV dysfunction. Patients were excluded from analyses if they had not received a cardiac catheterization, were referred for a coro- nary artery bypass graft, had failed a percutaneous coronary intervention, or showed no evidence of cardiomyopathy on either their cardiac catheterization or echocardiogram.

Ultimately, a total of 177 TTS patients were included for study analysis. Patients' charts were also reviewed to extract sociodemographic information, clinical data, transthoracic echocardiogram, and cardiac catheterization results. The authors used the Killip classification method to stratify sample patients' by clinical signs of heart failure. ${ }^{24}$

In this study, primary TTS was defined as patients whose primary reason for presentation was due to TTS cardiomyopathy. Secondary TTS was defined as patients who developed TTS secondary to another critical physical illness during admission. 2,3

Patients' degree of CAD was quantified by report with no abnormal coronary arteries assigned a value of 0 , minimal or mild CAD assigned a value of 1 , moderate CAD or any lesion $>50 \%$ stenosis given a value of 2 , severe CAD or any lesion $>90 \%$ or three or more lesions $>70 \%$ assigned a value of 3. 22,23

Echocardiogram reports were reviewed for instances of any mitral regurgitation, aortic stenosis, and aortic regurgitation. Degree of valvular dysfunction was assigned a value: none or trace was given a value of 0 , mild was assigned a value of 1 , moderate a value of 2 , and severe a value of 3.25

Data were analyzed by statisticians in the authors' clinical research department using SPSS version $23 .^{26}$ Dependent variables measured on a continuous scale were analyzed for significance using the independent samples t-test assuming normal distribution. Categorical data were analyzed for significance using the chi-square test for independence. Most of the results reported in this paper are presented as continuous variables expressed as a mean \pm standard deviation or counts with population as appropriate.

The authors' primary analytic outcome was to identify significant predictors of in-hospital mortality. Secondary analytic outcomes included predictors of ejection fraction (EF) $<35 \%$ and to identify medical therapy used during patients' hospital course to examine associations with outcomes. $^{27}$

\section{RESULTS}

A total of $\mathrm{N}=177$ sample patients who met TTS criteria were identified. There were 10 (5.65\%) instances of patient mortality. Overall, 79 (44.7\%) patients demonstrated the typical apical ballooning type pattern. Primary TTS represented 155 (87.6\%) patients while secondary TTS represented $22(12.4 \%)$ patients. Mortality occurred in nine (5.8\%) primary TTS patients and one (4.7\%) secondary TTS patient. The most common causes of secondary TTS included gastrointestinal bleed, sepsis, and post-surgical causes. Etiologies of patient death were determined to be from ventricular tachycardia/fibrillation arrest in $40 \%$, pulseless electrical activity arrest $50 \%$, and undetermined in $10 \%$.

Of the 45 (25.4\%) of TTS patients identified as presenting with a ST segment elevation myocardial infarction, 18 (40\%) were in the mortality subgroup versus 11 (24.5\%) in the non-mortality subgroup. Medications used during 
Table 1 Demographics and Clinical Characteristics of Study Population Stratified By Mortality versus NonMortality Subgroups

\begin{tabular}{|c|c|c|c|}
\hline & Mortality $(n=10)$ & Non-Mortality $(n=167)$ & p-value \\
\hline & Mean $( \pm S D)$ & Mean $( \pm S D)$ & \\
\hline Age & $66.4( \pm 16.38)$ & $63.73( \pm 13.41)$ & 0.547 \\
\hline $\mathrm{BMI}$ & $31.99( \pm 9.11)$ & $29.29( \pm 7.63)$ & 0.285 \\
\hline BSA & $2.06( \pm 0.34)$ & $1.92( \pm 0.32)$ & 0.148 \\
\hline LOS & $7.8( \pm 8.12)$ & $5.13( \pm 6.75)$ & 0.230 \\
\hline Day of Cardiac Catheterization & $1.8( \pm 1.03)$ & $2.3( \pm 2.2)$ & 0.476 \\
\hline Clinical History ** & Frequency & Frequency & $\mathrm{p}$-value \\
\hline Male & $50.00 \%$ & $22.80 \%$ & 0.064 \\
\hline Female & $50.00 \%$ & $77.20 \%$ & 0.064 \\
\hline Previous $\mathrm{PCl}$ & $10.00 \%$ & $9.60 \%$ & 0.999 \\
\hline Previous CABG & $40.00 \%$ & $2.40 \%$ & 0.001 \\
\hline PAD & $10.00 \%$ & $1.80 \%$ & 0.209 \\
\hline CVA & $10.00 \%$ & $6.00 \%$ & 0.483 \\
\hline Family History of CAD & $10.00 \%$ & $11.40 \%$ & 0.999 \\
\hline Diabetes & $40.00 \%$ & $20.40 \%$ & 0.225 \\
\hline HTN & $70.00 \%$ & $65.90 \%$ & 0.999 \\
\hline COPD & $30.00 \%$ & $16.80 \%$ & 0.383 \\
\hline OSA & $20.00 \%$ & $7.20 \%$ & 0.181 \\
\hline Smoker & $60.00 \%$ & $57.50 \%$ & 0.999 \\
\hline History of cancer & $50.00 \%$ & $13.80 \%$ & 0.010 \\
\hline History of heart failure & $20.00 \%$ & $8.40 \%$ & 0.225 \\
\hline ESRD & $40.00 \%$ & $13.20 \%$ & 0.042 \\
\hline Depression & $20.00 \%$ & $32.30 \%$ & 0.507 \\
\hline
\end{tabular}

* Significant $\mathrm{p}$ values appear in bold font.

*** Body mass index (BMI), Body surface area (BSA), Length of stay (LOS), Percutaneous coronary intervention (PCI), Coronary artery bypass graft (CABG), Peripheral artery disease (PAD), Cerebrovascular accident (CVA), Coronary artery disease (CAD), Hypertension (HTN), Chronic obstructive pulmonary disease (COPD), Obstructive sleep apnea (OSA), End-stage renal disease (ESRD).

the hospital course were analyzed between patients in the mortality and non-mortality subgroups. Overall, 79 (44.6\%) of total sample patients had been placed on atorvastatin, 88 (49.7\%) patients were placed on metoprolol tartrate, 60 (33.9\%) of patients were placed on carvedilol, and 65 (36.7\%) of patients were placed on Lisinopril.

Of the total sample, 33 (18.6\%) patients showed moderate-to-severe mitral regurgitation (MR) on their echocardiogram. The mortality rate was $9.1 \%$ for patients with moderate-to-severe MR versus $4.9 \%$ in patients with mild or less MR. Patients with moderate-to-severe MR were significantly older $(\mathrm{p}=0.016)$, had a significantly lower EF ( $\mathrm{p}=$ $0.008)$, lower admission hemoglobin $(p=0.001)$, higher admission BUN $(\mathrm{p}=0.004)$, and higher admission creatinine $(\mathrm{p}$ $=0.011)$. There were no other significant differences identified between subgroups, although left ventricular end-diastolic pressure (LVEDP) levels were somewhat higher in patients with moderate-to-severe MR, although this difference was not statistically significant $(p=0.071)$.

\section{MORTALITY VERSUS NON-MORTALITY SUBGROUPS}

Baseline data between the mortality and non-mortality subgroups are represented in Table 1 . In the mortality subgroup, $50 \%$ of the population was male versus $22.8 \%$ in the non-mortality subgroup $(\mathrm{p}=0.064)$. Apical ballooning was found in $30 \%$ of patients in the mortality subgroup versus $43.7 \%$ in the non-mortality subgroup $(\mathrm{p}=0.496)$.

Table 2 demonstrates the clinical, laboratory, and echocardiographic parameters obtained between the mortality and non-mortality subgroups. As shown in this table, patients who died during hospitalization had significantly lower mean admission hemoglobin levels ( $p<0.001)$, lower admission hematocrit levels $(p=0.001)$, lower admission sodium levels $(\mathrm{p}=0.02)$, higher admission BUN levels $(\mathrm{p}=$ 0.009 ), lower admission glomerular filtration rate levels ( $p$ $=0.016)$, higher admission lactic acid $(\mathrm{p}<0.001)$, and lower admission albumin levels ( $\mathrm{p}<0.001)$.

Table 3 depicts the echocardiographic and cardiac catheterization data. Patients who died during hospitalization had a non-significant lower average EF of 36.5 (SD $16.5) \%$ versus an average EF of 44.15 (SD 15.94)\% in the non-mortality subgroup ( $p=0.143$ ). There was, however, a significantly higher degree of CAD in the mortality group versus the non-mortality group $(p=0.012)$. 
Table 2 Cardiac Biomarkers, Admission Vitals and Laboratory Data for the TTS Subgroups

\begin{tabular}{|c|c|c|c|}
\hline \multirow[t]{2}{*}{ Cardiac Biomarkers } & Mortality $(n=10)$ & Non-Mortality $(n=167)$ & $\mathrm{p}$-value \\
\hline & Mean ( \pm SD) & Mean ( \pm SD) & \\
\hline Average Troponin (ng/ml) & $0.43( \pm 0.44)$ & $2.28( \pm 6.74)$ & 0.440 \\
\hline Peak Troponin (ng/ml) & $0.45( \pm 0.44)$ & $3.5( \pm 11.05)$ & 0.410 \\
\hline Admission Troponin (ng/ml) & $0.35( \pm 0.46)$ & $0.76( \pm 1.76)$ & 0.490 \\
\hline Average BNP (pg/ml) & $2184.38( \pm 3406.08)$ & $3379.62( \pm 8204.52)$ & 0.945 \\
\hline Peak BNP (pg/ml) & $3164.31( \pm 3444.76)$ & $4335.62( \pm 10860.48)$ & 0.580 \\
\hline Admission BNP (pg/ml) & $2095.37( \pm 3284.15)$ & $3427.63( \pm 8389.59)$ & 0.658 \\
\hline \multicolumn{4}{|l|}{ Admission Vitals } \\
\hline Admission SBP (mmHg) & $119.9( \pm 47.51)$ & $143.06( \pm 35.87)$ & 0.053 \\
\hline Admission DBP $(\mathrm{mmHg})$ & $58.5( \pm 27.09)$ & $80.66( \pm 22.23)$ & 0.003 \\
\hline Admission HR (bpm) & $86.00( \pm 19.56)$ & $88.94( \pm 24.99)$ & 0.716 \\
\hline \multicolumn{4}{|l|}{ Laboratory Data } \\
\hline Cortisol level $(\mu \mathrm{g} / \mathrm{ml})$ & $36.73(18.82)$ & $25.64( \pm 16.38)$ & 0.332 \\
\hline TSH (ulU/ml) & $1.63( \pm 0.44)$ & $2.35( \pm 2.91)$ & 0.671 \\
\hline Free Thyroxine (ng/dl) & $0.79( \pm 0.07)$ & $1.09( \pm 0.43)$ & 0.333 \\
\hline HDL level (mg/dl) & $46.42( \pm 18.34)$ & $45.64( \pm 14.81)$ & 0.901 \\
\hline LDL level (mg/dl) & $52.41( \pm 17.81)$ & $87.06( \pm 34.34)$ & 0.016 \\
\hline \multicolumn{4}{|c|}{ Admission Laboratory Data } \\
\hline Admission hemoglobin (g/dl) & $11.31( \pm 2.08)$ & $13.59( \pm 1.87)$ & 0.001 \\
\hline Admission sodium (mmol/L) & $135.10( \pm 3.93)$ & $137.61( \pm 3.24)$ & 0.020 \\
\hline Admission BUN (mg/dl) & $28.60( \pm 16.59)$ & $19.17( \pm 10.51)$ & 0.009 \\
\hline Admission creatinine (mg/dl) & $1.65( \pm 0.91)$ & $1.07( \pm 1.09)$ & 0.101 \\
\hline Admission GFR & $49.80( \pm 28.44)$ & $71.21( \pm 27.04)$ & 0.016 \\
\hline Admission lactic acid (mmol/L) & $7.59( \pm 5.18)$ & $2.39( \pm 2.11)$ & 0.001 \\
\hline Admission albumin (g/dl) & $3.22( \pm 0.46)$ & $3.89( \pm 0.49)$ & 0.001 \\
\hline \multicolumn{4}{|l|}{ Average Laboratory Data } \\
\hline Average hemoglobin (g/dl) & $10.45( \pm 1.89)$ & $12.52( \pm 1.61)$ & 0.001 \\
\hline Average sodium (mmol/L) & $135.50( \pm 4.48)$ & $138.55( \pm 2.60)$ & 0.001 \\
\hline Average BUN (mg/dl) & $37.65( \pm 19.59)$ & $17.69( \pm 7.62)$ & 0.001 \\
\hline Average creatinine (mg/dl) & $2.01( \pm 1.20)$ & $0.97( \pm 1.06)$ & 0.003 \\
\hline Average GFR & $54.50( \pm 58.15)$ & $80.60( \pm 28.03)$ & 0.009 \\
\hline Average lactic acid (mmol/L) & $5.77( \pm 0.87)$ & $1.84( \pm 0.93)$ & 0.001 \\
\hline Average albumin (g/dl) & $2.86( \pm 0.59)$ & $3.64( \pm 0.55)$ & 0.001 \\
\hline
\end{tabular}

* Significant $\mathrm{p}$ values appear in bold font

** Brain natriuretic peptide (BNP), Systolic blood pressure (SBP), Diastolic blood pressure (DBP), Heart rate (HR), Millimeters of mercury (mmHg), Beats per minute (bpm), Thyroid stimulating hormone (TSH), High density lipoprotein (HDL), Low density lipoprotein (LDL), Blood urea nitrogen (BUN), Glomerular filtration rate (GFR)

EF $<35 \%$ VERSUS EF $\geqslant 35 \%$ SUBGROUPS

Further data analysis was performed comparing EF $<35 \%$ versus $\mathrm{EF} \geqslant 35 \%$. (Table 4 ) In patients with an $\mathrm{EF}<35 \%$ the mortality rate was $8.2 \%$. In patients with an $\mathrm{EF}<35 \%$ the degree of CAD was higher ( $p=0.011)$, Killip classification was also higher $(p=0.002)$, and LVEDP levels were higher ( $p$ $=0.005)$ than in patients with an $\mathrm{EF} \geqslant 35 \%$. There were also significant differences in admission brain natriuretic peptide (BNP) lab values $(p=0.009)$, peak BNP $(p=0.005)$, and average BNP levels $(p=0.003)$. Other admission laboratory data in patients with an $\mathrm{EF}<35 \%$ were significantly different than in patients with an $\mathrm{EF} \geqslant 35 \%$ (Table 4).

\section{UNIVARIATE LOGISTIC REGRESSION}

Variables that achieved statistical significance (i.e., $p$ values $<0.05$ ) from the univariate analysis were considered for inclusion in the non-parametric logistic regression model for in-hospital mortality. Variables that achieved significance from the model are found in Table 5. The HosmerLemeshow goodness of fit test was used to ensure the model appropriately fit the data. ${ }^{28}$ As seen in Table 5 , the $\mathrm{p}$ values calculated from variations in each of the admission labs of were found to be statistically significant predictors of hospitalization mortality ( $\mathrm{p}$ values ranging from 0.028 to 0.001). 
Table 3 Echocardiographic Data and Cardiac Catheterization Data for the Mortality and Non-Mortality Subgroups

\begin{tabular}{|c|c|c|c|}
\hline \multirow[t]{2}{*}{ Echocardiographic Data } & Mortality $(n=10)$ & Non-Mortality (n=167) & \multirow[t]{2}{*}{ p-value } \\
\hline & Mean ( $\pm S D)$ & Mean ( $( \pm S D)$ & \\
\hline Ejection Fraction (\%) & $36.5( \pm 16.5)$ & $44.15( \pm 15.94)$ & 0.143 \\
\hline Diastolic Dysfunction & $1.0( \pm 1.05)$ & $0.73( \pm 0.82)$ & 0.452 \\
\hline Aortic stenosis ${ }^{* * * *}$ & $0.30( \pm 0.95)$ & $.13( \pm 0.54)$ & 0.347 \\
\hline Aortic regurgitation ${ }^{* * * *}$ & $0.2( \pm 0.54)$ & $0.13( \pm 0.39)$ & 0.580 \\
\hline Mitral regurgitation**** & $1.0( \pm 1.05)$ & $0.73( \pm 0.82)$ & 0.326 \\
\hline $\mathrm{RVSP}$ (mmHg) & $37.04( \pm 8.83)$ & $36.55( \pm 11.66)$ & 0.907 \\
\hline \multicolumn{4}{|l|}{ Cardiac Catheterization Data } \\
\hline LVEDP (mmHg) & $24.5( \pm 9.99)$ & $19.6( \pm 6.54)$ & 0.082 \\
\hline Degree of $C A D^{* * * * *}$ & $2.67( \pm 1.32)$ & $1.93( \pm 0.83)$ & 0.012 \\
\hline
\end{tabular}

* Significant $\mathrm{p}$ values appear in bold font.

***** Right ventricular systolic pressure (RVSP), left ventricular end-diastolic pressure (LVEDP), Coronary artery disease (CAD).

\section{COX PROPORTIONAL HAZARDS REGRESSION}

When comparing the mortality and non-mortality subgroups, the statistically significant variables from univariate logistic regression (Table 5) were considered for analysis in a multivariate cox regression model. Ultimately, admission hemoglobin, admission creatinine, admission systolic blood pressure, and admission albumin were included in the final Cox regression model. Of these variables, admission hemoglobin was significant with a hazard ratio of 0.760 (95\% CI: 0.594-0.972, $\mathrm{p}=0.029$ ). Thus, for each unit decrease in admission hemoglobin in TTS patients there was an associated increase in in-hospital mortality by $24 \%$

\section{MULTIVARIATE LINEAR REGRESSION}

A simple linear regression was calculated to predict differences between the $\mathrm{EF}<35 \%$ and $\mathrm{EF} \geqslant 35 \%$ subgroups of sample patients. The statistically significant variables that were considered were taken from the univariate logistic regression results and entered into a multivariate linear regression model. Ultimately, degree of CAD, MR, admission hemoglobin, and admission creatinine were the variables used in the model. A significant regression equation was found $\mathrm{F}(4,7.189)=4.813, \mathrm{p}<0.001$, with an $\mathrm{R}^{2}$ of 0.151 . Although not depicted in a separate table degree of $C A D(B=-0.166$, $p=0.024)$, mitral regurgitation $(B=-0.199, p=0.009)$, and admission hemoglobin $(B=0.169, p=0.025)$ were shown to be significant predictors of having an $\mathrm{EF}<35 \%$.

\section{DISCUSSION}

TTS is a transient heart failure syndrome that can typically present with complications at similar rates to ACS patients in hospital settings. ${ }^{6-8,24}$ The in-hospital TTS mortality rate in this study was $5.65 \%$ which was similar to previous studies. $5,6,8,9,11,12$

The presence of co-morbid conditions has also been associated with poor outcomes in TTS. ${ }^{7,29-31}$ In their 2010 ar- ticle, Brinjikji et al, reported renal impairment as a critical predictive factor related to TTS-related mortality. ${ }^{29}$ Consistent with this 2010 study, our sample patients with ESRD also had a significantly higher mortality rate. Endothelial dysfunction, oxidant stress, vascular calcifications, and inflammation from renal dysfunction also likely contribute to worse TTS patient outcomes. ${ }^{32}$

Previous studies have demonstrated a similarly higher incidence of cancer in TTS compared to the general population. ${ }^{33,34}$ In one 2016 study, $28.5 \%$ of TTS patients were diagnosed with cancer, and the presence of cancer was found to be an independent predictor of cardiac and all-cause death in TTS. ${ }^{35}$ Although this pathologic mechanism is not well understood, it has been postulated that possessing a malignancy may enhance patients' neurohormonal activation and the inflammatory response during the acute phase of TTS. ${ }^{35}$

In our study, degree of CAD was significantly associated with higher degree of cardiomyopathy and in-hospital mortality. The Mayo Clinic criteria indicate that the absence of obstructive CAD is still possible with a diagnosis of TTS, and previous studies have reported non-CAD levels in up to $19 \%$ of TTS patients. ${ }^{5,18,36,37}$ Modern techniques such as fractional flow reserve and intravascular ultrasound have now provided objective measurements to evaluate potential obstructive lesions to help delineate TTS from obstructive CAD. Parodi et al (2013) stated that TTS and CAD were not mutually exclusive and up to $10 \%$ of TTS patients may have been missed due to their exclusion of patients with documented CAD. ${ }^{37}$

It remains especially important to recognize the presence of CAD in TTS as it is associated with poor outcomes. In Bill et al. (2017), CAD in TTS patients had significantly lower EF, higher risk of cardiogenic shock was an independent predictor of mortality when compared to non-CAD TTS patients. ${ }^{36}$ In 2016, the European Society of Cardiology recognized CAD as a risk factor for more severe heart failure during acute TTS episodes. ${ }^{2}$

Lower hemoglobin levels place an extra demand on cardiac output and decrease blood viscosity (i.e., thickness), 
Table 4 Clinical Variables, Echocardiographic Data, Cardiac Biomarkers, Admission Laboratory Data, Laboratory Data for the Sub-Group Analysis EF $<35 \%$ versus EF $\geqslant 35 \%$

\begin{tabular}{|c|c|c|c|}
\hline & $E F<35 \%(n=49)$ & $E F \geq 35 \%(n=128)$ & p-value \\
\hline & Mean ( \pm SD) & Mean ( \pm SD) & \\
\hline LOS (days) & $7.41( \pm 5.36)$ & $4.46( \pm 7.17)$ & 0.010 \\
\hline $\operatorname{LVEDP}(\mathrm{mmHg})$ & $22.26( \pm 7.34)$ & $18.88( \pm 6.28)$ & 0.005 \\
\hline Degree of CAD & $2.24( \pm 1.00)$ & $1.86( \pm 0.79)$ & 0.011 \\
\hline Killip classification & $2.31( \pm 1.19)$ & $1.72( \pm 1.06)$ & 0.002 \\
\hline \multicolumn{4}{|c|}{ Echocardiographic Data } \\
\hline Diastolic Dysfunction & $0.91( \pm 1.08)$ & $0.76( \pm 0.85)$ & 0.505 \\
\hline Mitral regurgitation & $1.13( \pm 0.95)$ & $0.61( \pm 0.75)$ & 0.001 \\
\hline $\mathrm{RVSP}(\mathrm{mmHg})$ & $40.48( \pm 11.72)$ & $34.99( \pm 11.05)$ & 0.012 \\
\hline \multicolumn{4}{|l|}{ Cardiac Biomarkers } \\
\hline Average Troponin (ng/ml) & $2.93( \pm 8.88)$ & $1.91( \pm 5.48)$ & 0.371 \\
\hline Admission Troponin (ng/ml) & $0.93( \pm 2.47)$ & $0.67( \pm 1.33)$ & 0.371 \\
\hline Average BNP (pg/ml) & $6289.49( \pm 11303.98)$ & 1357.91( \pm 3145.84$)$ & 0.003 \\
\hline Peak BNP (pg/ml) & $7783.81( \pm 14790.68)$ & $1703.02( \pm 4736.49)$ & 0.005 \\
\hline Admission BNP (pg/ml) & $5954.38( \pm 10970.68)$ & $1534.04( \pm 4645.63)$ & 0.009 \\
\hline \multicolumn{4}{|c|}{ Admission Laboratory Data } \\
\hline Admission hemoglobin ( $\mathrm{g} / \mathrm{dl}$ ) & $12.61( \pm 2.33)$ & 13.79( $( \pm 1.67)$ & 0.001 \\
\hline Admission sodium (mmol/L) & $136.59( \pm 4.36)$ & $137.81( \pm 2.76)$ & 0.029 \\
\hline Admission BUN (mg/dl) & $22.61( \pm 14.08)$ & $18.56( \pm 9.55)$ & 0.030 \\
\hline Admission creatinine (mg/dl) & $1.42( \pm 1.92)$ & $0.98( \pm 0.43)$ & 0.014 \\
\hline Admission GFR & $63.84( \pm 29.71)$ & $72.37( \pm 26.33)$ & 0.065 \\
\hline Admission albumin (g/dl) & $3.71( \pm 0.51)$ & $3.91( \pm 0.49)$ & 0.022 \\
\hline \multicolumn{4}{|l|}{ Laboratory Data } \\
\hline Average hemoglobin (g/dl) & $11.59( \pm 1.91)$ & $12.71( \pm 1.49)$ & 0.001 \\
\hline Average sodium (mmol/L) & $137.79( \pm 3.65)$ & $138.60( \pm 2.40)$ & 0.088 \\
\hline Average BUN (mg/dl) & $22.04( \pm 13.01)$ & $17.59( \pm 7.95)$ & 0.006 \\
\hline Average creatinine (mg/dl) & $1.34( \pm 1.92)$ & $0.91( \pm 0.47)$ & 0.020 \\
\hline Average albumin (g/dl) & $3.31( \pm 0.58)$ & $3.71( \pm 0.54)$ & 0.001 \\
\hline
\end{tabular}

* Significant p values appear in bold font.

** Length of stay (LOS), Left ventricular end diastolic pressure (LVEDP), Coronary artery disease (CAD), left ventricular outflow tract (LVOT), Right ventricular systolic pressure (RVSP), Brain natriuretic peptide (BNP), Glomerular filtration rate (GFR), Blood urea nitrogen (BUN),

leading to vascular (arterial and venous) dilation, which in turn leads to increased preload. ${ }^{38}$ In a chronic anemic state, LV hypertrophy can develop and ultimately lead to LV dilation and heart failure. ${ }^{30}$ Jankoswka et al, (2014) found iron deficiency is associated with higher mortality in a 12-month follow-up of heart failure patients. ${ }^{32,39,40}$

In our study, there was no significant difference found in BNP levels between the mortality and non-mortality sample subgroups. However, low BNP levels have been connected with favorable prognoses elsewhere. ${ }^{8,41}$ However, the correlation of BNP levels with hemodynamic parameters such as LVEDP are not as reliable in TTS. 2,7,42 Our study found that patients with an EF $<35 \%$ had significantly higher elevations of BNP and higher LVEDP values.

The mechanism of TTS is not entirely understood, although it is believed to be from a surge of catecholamines causing vascular dysfunction and direct myocardial stunning. Initial surges of catecholamines appear to correlate with NT-proBNP levels and the extent of LV systolic function. ${ }^{43,44}$ Since epinephrine and norepinephrine work on the beta receptors in the ventricular myocardium, it would appear beta blockers would be the ideal treatment of this syndrome in acute TTS. ${ }^{13}$ However, patients receiving beta blockers in earlier studies have not demonstrated a significant difference in 30-day mortality cardiovascular complications, or TTS recurrence. ${ }^{17,18}$

Inflammation also likely plays a significant role in the pathogenesis of TTS. ${ }^{35}$ Previous studies have suggested a benefit in ACEI and ARBs via the renin-angiotensin-aldosterone pathway and direct anti-inflammatory properties on the myocardium. ${ }^{18}$ The authors found no prospective studies to date examining their use in TTS.

\section{STUDY LIMITATIONS}

We should acknowledge several study limitations. This was 
Table 5 Univariate Logistic Regression for the Prediction of Patients with Mortality in Takotsubo Syndrome

\begin{tabular}{lllllll}
\hline Variable & Coefficient $(B)$ & Wald X & Sig. & Odds Ratio & \multicolumn{2}{c}{ 95.0\% Confidence Interval } \\
\cline { 5 - 6 } & & & & & Lower & Upper \\
Admission Diastolic BP & -0.053 & 0.018 & 0.003 & 0.948 & 0.915 & 0.983 \\
Admission Hemoglobin & -0.48 & 10.011 & 0.002 & 0.619 & 0.46 & 0.833 \\
Admission Hematocrit & -0.147 & 8.272 & 0.004 & 0.863 & 0.781 & 0.954 \\
Admission Sodium & -0.174 & 4.937 & 0.026 & 0.841 & 0.72 & 0.98 \\
Admission BUN & 0.049 & 5.787 & 0.016 & 1.05 & 1.009 & 1.093 \\
Admission GFR & -0.034 & 5.676 & 0.017 & 0.966 & 0.939 & 0.994 \\
Admission Lactic Acid & 0.444 & 4.828 & 0.028 & 1.559 & 1.049 & 2.318 \\
Admission Albumin & -2.72 & 12.544 & 0.001 & 0.066 & 0.015 & 0.297 \\
\hline
\end{tabular}

* Significant $\mathrm{p}$ values appear in bold font.

a single-center study with predominantly Caucasian population so our results may not be generalizable to other ethnic groups. This study was limited by its retrospective design and the sample subgroups may have differed in unmeasured ways. None of our sample patients underwent cardiac magnetic resonance imaging to differentiate between acute infarct or myocarditis as the etiology of their cardiomyopathy. ${ }^{2}$

Finally, due to our low number of mortality cases $(\mathrm{n}=10)$ our regression model may have contained more parameters that could be justified by the data. However, we included only minimal parameters found to be significant through univariate logistic regression to reduce our risk of using an over fitted predictive model. Finally, we did not examine right ventricular involvement in these cases which has been associated with a poor prognosis in TTS. ${ }^{45}$

\section{CONCLUSIONS}

In conclusion, these results demonstrate that patients who present with TTS on admission with hypotension, anemia, low albumin levels, elevated lactic acid and renal dysfunction appear to be at higher risk for in-hospital mortality. In addition, anemia may comprise one of the strongest predators of in-hospital mortality.

The lack of evidence-based therapies for this condition highlights the ongoing need for studies identifying those TTS patients at higher risk for complications. Further research is warranted to determine the most effective therapies for TTS patients so frequently already prone to health complications. Cardiology providers require further evidence from larger prospective research samples to identify optimal treatment approaches for these higher risk cardiology patients.

\section{DISCLOSURES}

The overall results of this study were presented as a poster presentation at the Statewide Campus System Poster Day, May 2017. This study was supported by the Genesys Regional Medical Center Department of Academic and Clinical Research.

\section{FUNDING}

The authors report no external funding source for this study.

\section{CONFLICT OF INTEREST}

The authors declare no conflict of interest.

\section{ACKNOWLEDGMENTS}

We acknowledge the support of Genesys Regional Medical Center's Department of Clinical Research, specifically, Dr. Kimberly Barber, PhD, and Tara Knisely, MPH who contributed data cleaning and statistical analyses.

We acknowledge Dr. Heather Kirkpatrick, PhD from the Department of Education who contributed to the revision of this manuscript. 


\section{REFERENCES}

1. Madhavan M, Prasad A. Proposed Mayo Clinic criteria for the diagnosis of Takotsubo cardiomyopathy and long-term prognosis. Herz. 2010;35(4):240-244.

2. Lyon AR, Bossone E, Schneider B, Sechtem U, Citro $\mathrm{R}$, Underwood SR, et al. Current state of knowledge on Takotsubo syndrome: A position statement from the Taskforce on Takotsubo Syndrome of the Heart Failure Association of the European Society of Cardiology. Eur J Heart Fail. 2016;18:8-27.

3. Khera R, Light-Mcgroary K, Zahr F, Horwitz PA, Girotra S. Trends in hospitalization for takotsubo cardiomyopathy in the United States. Am Heart J. 2016;172:53-63.

4. Prasad A, Lerman A, Rihal CS. Apical ballooning syndrome (Tako-Tsubo or stress cardiomyopathy): A mimic of acute myocardial infarction. Am Heart J. 2008;155:408-417.

5. Vriz O, Brosolo G, Martina S, Pertoldi F, Citro R, Mos L, et al. In-hospital and long-term mortality in Takotsubo cardiomyopathy: a community hospital experience. J Commun Hosp Intern Med Perspect. 2016;6(3).

6. Citro R, Rigo F, D’Andrea A, Ciampi Q, Parodi G, Provenza $\mathrm{G}$, et al. Correlates of acute heart failure, cardiogenic shock, and in-hospital mortality in TakoTsubo cardiomyopathy. JACC Cardiovasc Imaging. 2014;7(2):119-129.

7. Núñez-Gil IJ, Molina M, Bernardo E, Ibañez B, RuizMateos B, García-Rubira JC, et al. Tako-tsubo Syndrome and heart failure: Long-term follow-up. Rev Esp Cardiol. 2012;65(11):996-1002.

8. Murakami T, Yoshikawa T, Maekawa Y, Ueda T, Isogai T, Konishi Y, et al. Characterization of predictors of in-hospital cardiac complications of takotsubo cardiomyopathy: Multi-center registry from Tokyo CCU Network. J Cardiol. 2013;63(4):269-273.

9. Glaveckaitė S, Šerpytis P, Pečiūraitė D, Puronaitė R, Valevičienè N. Clinical features and three-year outcomes of Takotsubo (stress) cardiomyopathy: Observational data from one center. Hellenic J Cardiol. 2017:1-7.

10. Kurisu S, Kihara Y. Tako-Tsubo cardiomyopathy: Clinical presentation and underlying mechanism. J Cardiol. 2012;60(6):429-437.
11. Sobue Y, Watanabe E, Ichikawa T, Koshikawa M, Yamamoto M, Harada M, et al. Physically triggered Takotsubo cardiomyopathy has a higher in-hospital mortality rate. Int J Cardiol. 2017;235:87-93.

12. Singh K, Carson K, Shah R, Sawhney G, Singh B, Parsaik A, et al. Meta-analysis of clinical correlates of acute mortality in takotsubo cardiomyopathy. Am J Cardiol. 2014;113(8):1420-1428.

13. Lyon AR, Rees PSC, Prasad S, Poole-Wilson PA, Harding SE. Stress (Takotsubo) cardiomyopathy-a novel pathophysiological hypothesis to explain catecholamine-induced acute myocardial stunning. Nat Clin Prac Cardiovasc Med. 2008;5(1):22-29.

14. Wittstein IS, Thiemann DR, Lima JAC, Baughman KL, Schulman SP, Gerstenblith G, et al. Neurohumoral features of myocardial stunning due to sudden emotional stress. N Engl J Med. 2005;352(6):539-548.

15. Paur H, Wright PT, Sikkel MB, Tranter MH, Mansfield C, O’Gara P, et al. High levels of circulating epinephrine trigger apical cardiodepression in a 2-adrenergic receptor/Gi-dependent manner: A new model of Takotsubo cardiomyopathy. Circul. 2012;126(6):697-706.

16. Singh K, Akashi YJ, Horowitz J. Takotsubo Syndrome therapy: Current status and future directions. Int J Cardiol. 2016;5:23-29.

17. Isogai $T$, Matsui $H$, Tanaka $H$, Fushimi K, Yasunaga H. Early $\beta$-blocker use and in-hospital mortality in patients with Takotsubo cardiomyopathy. Heart. 2016;102(13):1029-1035.

18. Templin C, Ghadri JR, Diekmann J, Napp LC, Bataiosu DR, Jaguszewski M. Clinical features and outcomes of Takotsubo (stress) cardiomyopathy. $N$ Engl J Med. 2015;373(27):929-938.

19. Redmond M, Knapp C, Salim M, Shanbhag S, Jaumdally R. Use of vasopressors in Takotsubo cardiomyopathy: a cautionary tale. Br J Anaesth. 2013;110(3):487-488.

20. Abe Y, Tamura A, Kadota J. Prolonged cardiogenic shock caused by a high-dose intravenous administration of dopamine in a patient with takotsubo cardiomyopathy. Int J Cardiol. 2010;141(1):1-3.

21. ICD-9-CM Official Guidelines for Coding and Reporting. Center For Disease Control and Prevention. https://www.cdc.gov/nchs/data/icd/icd9c m guidelines 2011.pdf. Published 2011. 
22. O’Gara PT, Kushner FG, Ascheim DD. 2013 ACCF/ AHA Guideline for the Management of ST-Elevation Myocardial Infarction: Executive Summary: A Report of the American College of Cardiology Foundation/ American Heart Association Task Force on Practice Guidelines. J Amer Coll Cardiol. 2013;61(4):e80-e140.

23. Amsterdam EA, Wenger NK, Brindis RG. 2014 AHA/ACC Guideline for the Management of Patients With Non-ST-Elevation Acute Coronary Syndromes A Report of the American College of Cardiology/ American Heart Association Task Force on Practice Guidelines. J Amer Coll Cardiol. 2014;64(24):e142-e225.

24. Lee SR, Lee SE, Rhee TM, Park JJ, Cho H, Lee HY, et al. Discrimination of stress (Takotsubo) cardiomyopathy from acute coronary syndrome with clinical risk factors and coronary evaluation in realworld clinical practice. Int J Cardiol. 2017;235:154-161.

25. Nishimura RA, Otto CM, Bonow RO, Carabello BA, Erwin JP, Fleischer LA, et al. 2017 AHA/ACC Focused Update of the 2014 AHA/ACC Guideline for the Management of Patients With Valvular Heart Disease: A Report of the American College of Cardiology/ American Heart Association Task Force on Clinical Practice Guidelines. Circul. 2017;135(25).

26. IBM Corp. IBM SPSS Statistics for Windows, Version 23.0. 2015.

27. Recommendations for cardiac chamber quantification by echocardiography in adults: An update from the American Society of Echocardiography and the European Association of, Cardiovascular Imaging. Europ Heart J Cardiovasc Imag. 2016;17(4).

28. Hosmer DW, Lemeshow S. A goodness-of-fit test for the multiple logistic regression model. Commun in Statistics 1980. A10:1043-1069.

29. Brinjikji W, El-Sayed AM, Salka S. In-hospital mortality among patients with takotsubo cardiomyopathy: A study of the National Inpatient Sample 2008 to 2009. Am J Cardiol. 2012;164(2):215-221.

30. Tornvall P, Collste O, Ehrenborg E, JärnbertPetterson H. A case-control study of risk markers and mortality in Takotsubo stress cardiomyopathy. J Am Coll Cardiol. 2016;67(16):1931-1936.

31. Mahmoud AN, Al-Ani M, Saad M, Elgendy AY, Elgendy IY. Development and validation of a simple integer risk score for prediction of in-hospital mortality following Takotsubo syndrome. Heart Lung. 2016;45(6):510-514.
32. Foley RN, Parfrey PS, Sarnak MJ. Clinical epidemiology of cardiovascular disease in chronic renal disease. Am J Kidney Dis. 1998;32:S112-S119.

33. Sattler K, El-Battrawy I, Lang S, Zhou X, Schramm $\mathrm{K}$, Tülümen E, et al. Prevalence of cancer in Takotsubo cardiomyopathy: Short and long-term outcome. Int J Cardiol. 2017;238:159-165.

34. Burgdorf C, Kurowski V, Bonnemeier H, Schunkert $\mathrm{H}$, Radke PW. Long-term prognosis of the transient left ventricular dysfunction syndrome (Tako-Tsubo cardiomyopathy): Focus on malignancies. Eur J Hear Fail. 2008;10(10):1015-1019.

35. Girardey M, Jesel L, Campia U, Messas N, Hess S, Imperiale A, et al. Impact of malignancies in the early and late time course of Takotsubo cardiomyopathy. Circ J. 2016;80(10):2192-2198.

36. Bill V, El-Battrawy I, Schramm K, Ansari U, Hoffmann U, Haghi D, et al. Coincidental coronary artery disease impairs outcome in patients with takotsubo cardiomyopathy. QJM. 2017;00:1-6.

37. Parodi G, Citro R, Bellandi B, Del Pace S, Rigo F, Marrani M, et al. Tako-tsubo cardiomyopathy and coronary artery disease: a possible association. Coron Artery Dis. 2013;24:527-533.

38. Abraham WT, Fonarow GC, Albert NM, Stough WG, Gheorghiade M, Greenberg BH, et al. Predictors of In-Hospital Mortality in Patients Hospitalized for Heart Failure. J Am Coll Cardiol. 2008;52(5):347-356.

39. Jankowska EA, Kasztura M, Sokolski M, Bronisz M, Nawrocka S, Oleśkowska-Florek W, et al. Iron deficiency defined as depleted iron stores accompanied by unmet cellular iron requirements identifies patients at the highest risk of death after an episode of acute heart failure. Eur Heart J. 2014;35(36):2468-2476

40. Peterson PN, Rumsfeld JS, Liang L, Albert NM, Hernandez AF, Peterson ED, et al. A validated risk score for in-hospital mortality in patients with heart failure from the American Heart Association Get With the Guidelines Program. Circ Cardiovass Qual Outc. 2009;3(1):25-32.

41. Madhavan M, Borlaug BA, Lerman A, Rihal CS, Prasad A. Stress hormone and circulating biomarker profile of apical ballooning syndrome (Takotsubo cardiomyopathy): Insights into the clinical significance of B-type natriuretic peptide and troponin levels. Heart. 2009;95:1436-1341.

42. Killip T, Kimball JT. Treatment of myocardial infarction in a coronary care unit. Am J Cardiol. $1967 ; 20(4): 457-464$ 
43. Nguyen TH, Neil CJ, Sverdlov AL, Mahadavan G, Chirkov YY, Kucia AM, et al. N-terminal pro-brain natriuretic protein levels in Takotsubo cardiomyopathy. Am J Cardiol. 2011;108:1316-1321.

44. Ahmed KA, Madhavan M, Prasad A. Brain natriuretic peptide in apical ballooning syndrome (Takotsubo/stress cardiomyopathy): comparison with acute myocardial infarction. Coron Artery Dis.

2012;23:259-264.
45. Citro R, Bossone E, Parodi G, Rigo F, Nardi F, Provenza G, et al. Independent impact of RV involvement on in-hospital outcome of patients with Takotsubo syndrome. JACC Cardiovasc Imaging. 2016;9(7):894-895. 